\title{
POLÍTICAS DE COMBATE À POBREZA E AVALANCHE ULTRANEOLIBERAL: APORTES PARA REFLEXÃO*
}

Silene de Moraes Freire

Thaís Lopes Cortes

\section{Introdução}

Em maio de 2016, chegou ao fim o pacto de concertação social dos governos petistas (Lula - 2003 a 2010 e Dilma - 2011 a 2016), imposto pelo golpe de Estado que destituiu Dilma Rousseff da presidência do país (Demier, 2018). Após esse período, que representou parcas expressões de avanços para o segmento dos trabalhadores, tendo como marco a expansão e criação de políticas de combate à pobreza, como o programa social de grande magnitude, o Bolsa Família, tem-se a imposição de ataques contínuos aos direitos sociais e trabalhistas. As reflexões aqui apresentadas buscam fornecer aportes para compreensão dos nexos não casuais dessas políticas com os recentes ataques e retrocessos de enfrentamento da "questão social".

Graças aos governos de Fernando Henrique Cardoso, mas, sobretudo aos governos de Lula e Dilma, o século XXI, até a metade da sua segunda déca$\mathrm{da}$, parecia ter naturalizado o lugar das políticas sociais como forma paliativa de enfrentamento da pobreza, para alguns segmentos da classe trabalhadora. Como se sabe, o final do século XX, por decorrência do 'Estado mínimo', promoveu uma redução do alcance das políticas sociais e sua transmutação em políticas de "combate" à pobreza, não sendo por acaso que as naturalizações mencionadas no presente século ocorreram. Vale mencionar que esse fenômeno não foi uma particularidade brasileira. Conforme mencionou Silva (2012, p. 221- grifo nosso),

[...] o aumento do contingente de pobres ao redor do globo como consequência da nova organização do capital faz com que, aliado aos interesses de contrarreforma do Estado e das políticas sociais, o projeto da classe dominante busque uma atuação focalizada e segmentada, agindo especificamente sobre parcelas determinadas da classe trabalhadora. O capital,

*DOI - 10.29388/978-65-86678-20-8-0-f.27-52 
por meio de organismos internacionais, busca amenizar as contradições da superpopulação relativa e a resposta à 'questão da pobreza' passa a ser o centro dos seus objetivos.

A relevância dos processos de empobrecimento global na agenda pública internacional foi expressa na influência dos organismos internacionais. Um exemplo paradigmático do começo do século XXI é a convergência em torno dos temas centrais mencionados na Declaração do Milênio (2000), consensuada na Organização das Nações Unidas. Segundo José Paulo Netto (2013, p. 428):

Apesar desse espantoso minimalismo frente a uma "questão social" maximizada, os vários relatórios sobre o "desenvolvimento humano", regularmente preparados pelo PNUD, ainda que enfatizem "ganhos" deste programa, deixam claro que seus objetivos - reitere-se: minimalistas - não serão alcançados.

Sem dúvida, a crescente centralidade da pobreza nas políticas sociais pode ser percebida no plano internacional como recomendação dos organismos internacionais. Tal tendência se fortalece pela generalização de métodos padronizados internacionalmente para a medição empírica da pobreza que permitem estabelecer as magnitudes quantitativas do fenômeno em diferentes contextos sociais e regionais. A definição das linhas de pobreza e a produção da informação estatística é uma ferramenta fundamental na geração de políticas para a pobreza. Estas permitem reorientar e priorizar a distribuição de recursos públicos, enquanto fixam linhas objetivas (chamadas de métodos científicos) e subjetivas para a população pobre que é dividida entre os merecedores e não merecedores das novas formas de intervenção da política social. Simplificadamente, podemos dizer que aos merecedores são concedidas políticas compensatórias, aos não merecedores um leque de criminalizações que aprofundam o que Wacquant (2002) chamou de Estado Penal. Na mesma direção, José Paulo Netto (2013, p. 429) observou que, "a articulação orgânica de repressão às "classes perigosas" e assistencialização minimalista das políticas sociais dirigidas ao enfrentamento da "questão social" constitui uma das faces contemporâneas mais evidentes da barbárie atual".

Como observou Serna (2010), as 'políticas da pobreza' buscaram (re)definir a "questão social" e a política pública como um problema "técnico" com "razão prática". Assim, constroem a necessidade da intervenção técnica eficaz, que busca contar, identificar, selecionar e também capacitar pobres para "superar" as chamadas novas formas de empobrecimento e vulnerabilidade so- 
cial. Há nessa definição uma culpabilização do indivíduo pobre pela sua pobreza, descolando-o das condições reais que determinaram essa situação ${ }^{1}$.

As retóricas discursivas do combate à pobreza e a prática de alívio da mesma debilitam as sequelas mais graves, porém não alteram os fatores estruturais que geram a pobreza, ou seja, a reprodução da desigualdade econômica e os padrões de concentração na distribuição de riqueza e de poder no plano internacional. A proposta de integração social por meio de estratégias de redução da pobreza, não supera os pressupostos do liberalismo social de amortização e compensação social do desenvolvimento econômico como a seletividade, a focalização, e a ativação e a responsabilidade dos pobres e da sociedade civil nas políticas públicas de "superação" da pobreza.

Buscamos assim, fornecer reflexões para compreensão de como, no Brasil, políticas em plena consonância com o capital rentista, como as de combate à pobreza, contribuíram para uma despolitização favorecedora da imposição de ataques contínuos aos direitos sociais e trabalhistas nos governos ultraneoliberais recentes.

\section{A base ideológica das políticas de combate à pobreza}

No Brasil, foi desconcertante constatar o que parecia impossível: enfrentar a pobreza sem transformar a base econômica, tornou-se, como mencionou Leher (2012, p. 16), uma ideologia com forte poder hegemônico. Segundo o autor,

[...] tal configuração das políticas sociais objetiva que os setores dominantes possam manejar uma ordem social em que a concentração de renda é, necessariamente, avassaladora; os lucros dos bancos são astronômicos; o agronegócio conta com gordos subsídios públicos e com ativa proteção governamental, inclusive pelo empenho do Estado em estagnar

\footnotetext{
${ }^{1}$ Segundo Mauriel (2008), esse aspecto é um ponto crucial e relaciona-se a uma mudança conceitual da pobreza com base na perspectiva do economista indiano Amartya Sen, que sai da dimensão de renda que é externa aos indivíduos para se concentrar nas capacidades/características agregadas às pessoas. Com esse foco nas pessoas e nos seus potenciais de realização, a realidade social é analisada através das ações dos indivíduos e não pela estrutura do capital. Mauriel observa que o enfoque de Sen sobre a pobreza, traz consigo outro tipo de função para as políticas sociais. "Estas não precisam ser redistributivas [...], mas conseguir aumentar as capacidades, pois o aumento de renda seria alcançado pelos esforços próprios dos indivíduos no mercado" (Mauriel, 2008, p. 308).
} 
a reforma agrária, sendo parte crucial do celebrado PIB de países como o Brasil, e os saqueadores dos recursos naturais contam com subsídios e infraestrutura pública no escopo do Plano de Infraestrutura Regional da América do Sul e do Programa de Aceleração do Crescimento.

A mistificação ideológica que preside a objetivação da chamada política de combate à pobreza, pode ser apreendida partindo do ponto de vista da totalidade e das mediações que particularizam o seu desenvolvimento histórico concreto. Como observou José Paulo Netto (2013), após o primeiro ano do Governo Lula já era nítido que jogávamos fora mais essa chance de enfrentar, numa perspectiva progressista, a reorientação da política macroeconômica, no sentido de retirá-la do controle parasitário-financeiro. Lula não tentou articular um conjunto de forças políticas e sociais que, assegurasse o enfrentamento com os beneficiários da orientação econômica do governo anterior. Ao contrário do esperado, Lula incrementou os aspectos regressivos dos mesmos.

Impossível não perceber que o Governo Lula fez das políticas para pobreza uma espécie de égide da política social, deixando claro que as inúmeras expressões da "questão social", iam perdendo sentido frente à consolidação da hegemonia burguesa dirigida por seus governos. Nesse contexto, é fácil observar, mais uma vez na história do país, uma moralização da "questão social", e de sua (re) transformação em nada mais do que um pauperismo normatizado como carência, vulnerabilidade, situação de risco, portanto, distante das determinações postas no conflito capital-trabalho.

Conforme destaca Mota (1995, p. 32), na correlação de forças entre as classes alargam-se as esferas de conflito e assim é possível a construção

[...] de outras formas de racionalidade, da socialização de valores, informações e visões do mundo e da sociedade, como uma condição para a formação de subjetividades coletivas, necessárias à adesão das classes a um projeto econômico, social, político e cultural que consolide a hegemonia de uma classe.

Conforme observou Maria Lúcia Werneck Vianna (2007, p. 16), a política social em voga no Brasil, sobretudo dos governos do PT, reduziu-se ao assistencialismo, à filantropia, à administração da miséria, esvaziando a atividade pública de sua rica significação original. A glorificação das recomendações dos organismos internacionais naturalizaram e banalizaram aspectos fundamentais da garantia dos direitos. Nesse cenário, as políticas sociais são apresentadas como algo caro, que desperdiça recurso, penaliza investimentos e não alcançam 
os pobres. Assim, como menciona a autora, inovadoras são "as ações que se dirigem a indivíduos, a grupos específicos, a segmentos da população pobre que devem ser tratados de modo diverso em respeito às diferenças que guardam entre si" (idem). O axioma dessas políticas define, de modo reducionista, a "questão social" como a pobreza, que é compreendida como a ausência de dotes correlatos a escolaridade, aos cuidados com a própria saúde e a capacidade para administrar a renda. Para tanto, supõe-se que uma vez adquiridos permite a superação da pobreza, ressalta a autora. Além disso, explica Maria Lúcia Werneck Vianna, no fundo, o interesse dos governos que implementam essas políticas é formar produtores-consumidores mais do que resguardar direitos civis. A inclusão social defendida pelos programas e políticas sociais voltados para a pobreza traduz-se na inclusão ao mercado. "Não por acaso o indivíduo é incitado a agir por si só, em uma tática de empowerment (conferir-lhe poder de decisão e autonomia)" (ibidem).

Assim sendo, não é coincidência que as organizações estimuladas pelas agências multilaterais, que proliferaram nos governos do PT, embora não tenham sido uma invenção desse governo, tenham se voltado para a ação social, mas que efetivamente não possuam capacidade de promover elementos que alterem as regras do jogo, ou seja, não são capazes de acirrar o debate, de trazer novos elementos para reflexão, de mostrar a desigualdade como um ponto fundamental na disputa política e, por conseguinte, garantir e universalizar a cidadania. Essas organizações, em sua grande maioria não-governamentais (ONGs), parecem atuar apenas como uma espécie de mediação que remedia situações limite da pobreza. Com a oficialização desse debate na contemporaneidade, o que assistimos com a implementação dessas propostas foram as "políticas pobres para pobres". Quando o Estado não funciona como regulador, o mercado funciona de acordo com a sua própria lógica, de forma a erodir o espaço dos direitos, que consiste na regulação entre a ação do mercado e das necessidades de cidadania, sendo essa regulação provida pelo Estado, que é o definidor de qual arena da política de disputa de recursos.

Conforme observou Silvio Bava, nas últimas décadas do século passado já pudemos nos deparar com um arco de experiências que evidenciam um processo de mudança lento, mas que já apresentava no Brasil, a visão presente: "a ajuda aos coitadinhos, não tem nenhuma preocupação com a questão da cidadania” (Bava apud Dagnino e Alvarez, 2001, p. 53). É como se as ações promovidas, pelo que foi definido pelos organismos internacionais como sociedade civil,

[...] ajudassem a distanciar todos nós, mas, sobretudo a população atendi- 
da pelas mesmas, da construção de condições sociais mais igualitárias, que acaba meio que ficando escamoteada em nome de uma convocatória responsabilizando o todo, numa solidariedade esvaziada de um sentido político. (idem).

Assim sendo, não apenas é correto afirmar que a cultura brasileira do século XX representou um forte indício do profundo divórcio entre o povo e a nação, tornando, então, particularmente difícil o surgimento de uma autêntica consciência democrático-popular, como também é correto reconhecer que essa herança chega ao século XXI sendo aprofundada em plena consonância com os interesses do capital financeiro efetivados pela agenda neoliberal e mais recentemente pela sua versão mais perversa que aqui chamamos de ultraneoliberalismo.

É importante atentarmos para o fato de que, para universalizar a cidadania e aprofundar a democracia, é fundamental não só repensarmos o Estado e as políticas públicas em particular; faz-se também necessário atentarmos para a necessidade de uma prévia discussão a respeito dos conceitos atribuídos à sociedade civil. A "nova" problematização da relação mercado versus sociedade versus Estado fez ressurgir, com muito vigor, traços extremamente conservadores, incompatíveis com o equacionamento das questões que limitam o exercício da cidadania e, consequentemente, da democracia. Acreditar que o conservadorismo que hoje atravessamos é um fenômeno sem bases históricas é no mínimo desconhecer nosso passado, inclusive recente, que pulsa insepulto.

Não podemos esquecer que a ideologia que sustenta a proposta neoliberal se apropriou da dicotomia maniqueísta para demonizar tudo o que se refere à intervenção do Estado, inclusive, no que diz respeito ao Estado de direito e para justificar, de modo acrítico uma sociedade civil despolitizada, isto é, transformada numa mitologia denominada de "terceiro setor", que é falsamente situada para além do Estado e do mercado ${ }^{2}$.

$\mathrm{Na}$ mesma direção, Vera Telles fez importantes observações sobre esse fenômeno:

E é essa operação semântica que permite, sob a denominação genérica de Terceiro Setor, colocar como equivalentes entidades filantrópicas velhas e novas, organizações não-governamentais, associações de moradores e grupos comunitários de perfis diversos. Essa equivalência não é inteiramente falsa, é, na verdade, construída por referência a uma noção moral de responsabilidade, entendida como dever de solidariedade

\footnotetext{
${ }^{2}$ A respeito ver: Coutinho apud Semeraro (2001, p. 10).
} 
em relação aos pobres. Não por acaso, o discurso hoje corrente sobre o Terceiro Setor omite a tessitura democrática construída na interface entre Estado e sociedade por meio de espaços de participação, de representação e negociação política" (Telles, 2001, p. 160 - grifos nossos).

O amálgama da crise estrutural do Estado com o discurso satanizador do setor público diminuiu a capacidade deste para formular e executar políticas. "A burguesia, que no passado apoiou sua acumulação privada na gestão estatal e nas políticas Keynesianas, hoje se desdobra para amputar ao Estado toda sua capacidade regulatória” (Borón, 1995, p. 78). Sua estratégia de dominação - articulada nos diferentes cenários nacionais com a estratégia das frações hegemônicas do capital imperialista - foi facilitada, conforme registrou AtilioBorón, pelo fenomenal retrocesso experimentado pelo movimento operário em escala planetária. Tal situação "precipitou uma ofensiva sem precedentes destinada a desviar o caminho iniciado com a Grande Depressão de 1929, deslocando o centro de gravidade da relação Estado-mercado em direção deste último" (idem). ${ }^{3}$ Nesse contexto, quando olhamos para trás observamos como foi clara a tendência de deslocamento das ações governamentais públicas - de abrangência universal - no trato das necessidades sociais em favor de sua privatização.

Esse processo de transferência da satisfação das necessidades sociais da esfera do direito público para a esfera do direito privado ocorreu à medida que se tem a derruição das lutas e das conquistas sociais ora, extensivas a todo o conjunto da sociedade.

O desenho e a implementação das políticas para pobreza implicaram desafios, que não foram enfrentados, para a construção da cidadania social. A convivência de "diversas visões da pobreza" e das múltiplas concepções de cidadania se expressa de modo contraditório na construção permanente e em disputa das políticas sociais.

As políticas para a pobreza impuseram uma nova construção da subjetividade política e do estatuto da cidadania social. Assim, impulsionaram novas subjetividades: com a emergência de um estatuto para os "cidadãos pobres". Com isso, o estatuto da cidadania social também se transformou. Trata-se de uma reformulação dos direitos sociais como específicos a participação em determinados grupos sociais, direitos referidos não só a pessoa como também ao grupo familiar imediato de pertencimento. Como observou Serna (2010, p. 147

3 Isso explica, diz o autor, a onda de desregulamentações, liberalizações, aberturas indiscriminadas dos mercados e as privatizações mediante as quais os capitalistas se apropriaram das empresas estatais e dos serviços públicos mais rentáveis. 
- grifos nossos) essas políticas tratam "de direitos sociais transitórios e plausíveis de serem suspensos, sujeitos a condições e contextos sociais que se esperam se transformem em um curto prazo".

Esta forma de definição de políticas de "mínimos sociais" embasa a eficácia da gestão pública na capacidade de administrar diversos mecanismos de seletividade social dos programas para identificação de beneficiários e determinação dos alcances reais da cidadania social.

Vemos assim que as definições de sociedade civil engendradas pelas políticas para pobres não eram aleatórias. As mesmas se apresentaram e se apresentam enquanto uma decisão política sob o sustentáculo da necessidade de se obter uma profunda redefinição do papel estatal e de uma redistribuição regressiva do poder, que beneficie os setores mais poderosos da sociedade. A delegação das responsabilidades públicas depende, aprioristicamente, de forma direta, da intervenção estatal. Nessa medida, o que se pretende não é o "afastamento" da intervenção estatal, mas sim, a sua reconfiguração. Tal processo afetou e afeta cada dia mais profundamente e diretamente as políticas sociais, cuja finalidade passa a ser proteger os pobres, sendo contraditória em relação à formulação já clássica de Polanyi ${ }^{4}$.

Nesse sentido, conforme assinalou Pablo Gentili (2000), as políticas sociais focalizadas promovidas pelos governos neoliberais constituem-se numa das dimensões que assume o processo privatizador no campo social. Melhor dizendo, como demonstrou Freire (2006), a notoriedade atribuída por essas políticas a sociedade civil tem promovido a emergência de novas formas institucionais que conduzem a uma redefinição do espaço público (como esfera não-estatal), do sentido atribuído ao direito social como direito universal, tanto quanto da própria noção de cidadania e democracia. Ou seja, estamos diante de um sintoma muito mais grave que o tão mencionado efeito (neo)liberal de redução do gasto público. É esse nítido sintoma que abre e fundamenta os caminhos do que estamos chamando de avalanche ultraneoliberal.

\footnotetext{
4 "Para Polanyi, como se sabe, as ações governamentais de cunho social - voltadas ou não apenas para os pobres - têm historicamente por função proteger a sociedade como um todo dos riscos que a expansão do mercado acarreta, em particular das desigualdades, que, no limite, ameaçam a própria integridade do tecido social. Em fina sintonia com a primeira, salta aos olhos uma segunda premissa, que, definindo política social como política assistencial, a associa à bondade. Esse entendimento, que também se contrapõe ao de Polanyi - e que contraria todos os clássicos da teoria política desde Maquiavel -, possibilita a seus seguidores desconsiderar como sociais outras políticas fundamentais para o enfrentamento da "questão social", como transportes, saneamento e, especialmente, previdência social” (Vianna, 2007, p. 3).
} 
A continuidade dessas políticas reféns das ações delegatórias à sociedade civil fizeram com que o debate oficial e a ação governamental permanecessem "restritos a alternativas pobres para pobres, sem produzir efeitos sequer compensatórios efetivos nem muito menos tocar na estrutura que gera a desigualdade social e a pobreza em nosso país" (Soares, 2000, p. 3). Em suma, impossível não crer que a ênfase nessas políticas nos distanciou ainda mais da cidadania e do aprofundamento da democracia.

Sob esta tendência, os estados da América Latina potencializam a regressão antidemocrática, que os fazem caminhar vazios dos seus conteúdos democráticos e em debilidade com a sua capacidade de intervenção.

É preciso rever a utilização de determinados conceitos para redefinirmos os termos dos enfrentamentos sociais, na medida em que as referências centrais mudam de sentido. Estado, sociedade civil - entre outros - são conceitos que, no marco dos grandes enfrentamentos das forças sociais do capitalismo, merecem todo o rigor em função de sua particularidade histórica.

O modo como ocorre o enfrentamento da "questão social" no Brasil possui particular importância quando percebemos a utilização que as classes dominantes fazem desta questão em cada momento da nossa história. Por isso, faz-se mister apreendermos as determinações históricas da "questão social", tornadas mais complexas nas suas formas de expressões, sendo claro que no cenário atual a "velha" "questão social" se metamorfoseia e assume novas roupagens. Ela evidencia hoje a imensa fratura entre o desenvolvimento das forças produtivas do trabalho social e as relações sociais que o sustentam ${ }^{5}$.

Diferentemente da experiência dos países europeus, em solo brasileiro a cidadania não se constituiu historicamente, como demonstrado por José Murilo de Carvalho (2001). Ao analisarmos a especificidade brasileira, constatamos que as relações do favor e da dependência atravessam a nossa formação política. Aqui, as classes dominantes se acostumaram a fazer do Estado brasileiro o seu instrumento econômico privado. Assim, o discurso neoliberal (em período recente ultraneoliberal) tem assombrosa recepção ao atribuir o título de moderno, ao que existe de mais conservador e atrasado em nossa sociedade: tornar o interesse privado a medida de todas as coisas, obstaculizando a esfera pública e anulando a dimensão ética da vida social pela recusa das obrigações e das res-

\footnotetext{
${ }^{5}$ Visto em perspectiva histórica ampla, é possível perceber que o aperfeiçoamento das formas de enfrentamento da "questão social" foi utilizado pelas elites dirigentes brasileiras como um elemento de fundamental importância para fazer a modernização capitalista seguir o seu caminho "passivo".
} 
ponsabilidades estatais ${ }^{6}$.

Contudo, essas análises não podem nos deixar esquecer que, mais do que uma coincidência, como observou Francisco de Oliveira (1999, p. 38),

[...] a construção da esfera pública, identificou-se ou se ergueu sobre as bases da regulação keynesiana. Esta esfera pública é, nos países capitalistas, sinônimo da democracia, simultânea ou concomitante, e ao longo do tempo os avanços sociais que mapeavam o acesso e a utilização do fundo público entravam num processo de interação com a consolidação de instituições políticas democráticas. Para todos os efeitos, pode-se considerar a construção da esfera pública e a democracia representativa como irmãs siamesas.

As particularidades das esferas pública e privada no território brasileiro não podem ser ignoradas. Para além da determinação das necessidades da reprodução do capital e da legitimação dos interesses burgueses, o Estado assume a particularidade de simbolizar um capitalismo dependente e periférico, que contém elementos patrimonialistas não vistos em outros Estados capitalistas que vivenciaram plenamente processos de revoluções burguesas. Nesta medida, cabe salientar que no Brasil, os governantes e demais ocupantes de cargos públicos, em qualquer nível de atuação tendem a considerar a coisa pública como patrimônio pessoal, utilizando-se de manifestações do clientelismo, do enriquecimento ilícito e da dilapidação da coisa pública, para benefício próprio ${ }^{7}$.

A avalanche ultraneoliberal demonstra que os problemas sociais aprofundados nessa quadra histórica que atravessamos não representam apenas uma retórica, mas um processo com profundas raízes em nossa sociedade. Assim sendo, no Brasil de hoje, faz-se urgente radicalizar a crítica e cobrar as promes-

\footnotetext{
${ }^{6}$ O processo de desenvolvimento do Brasil é marcado por um quadro de desigualdade estrutural, que se constitui enquanto uma particularidade histórica, na qual o moderno se constitui por meio do "arcaico", recriando a nossa herança histórica, que atualiza aspectos persistentes, isto é, do que há de arcaico, ao mesmo tempo em que o transforma no contexto (neo)liberal.

${ }^{7}$ Bem antes do advento do neoliberalismo no Brasil, a desprivatização do Estado já era um desafio que a esquerda pouco enfrentou. Com a sua implementação os desafios se potencializaram, ao passou que, nas últimas décadas, as classes dominantes imputaram papel elementar na formação da subjetividade antipública, representada por uma ideologia antiestatal, que demonstra desprezo pela "questão social" e pela necessidade do seu enfrentamento. Assim, como num processo mágico, demonstram que a acumulação do capital e o processo de reprodução social podem reproduzir-se sem a intervenção estatal. Para aprofundamento, ver: Freire, 2001.
} 
sas contidas no conceito de democracia. A questão real hoje é como desprivatizar o Estado, e esta seria a perspectiva de sua reforma (que significa ampliar os espaços da esfera pública não-burguesa, mas não no sentido de que cabe à sociedade realizar o que é dever do Estado, e sim no sentido rigoroso de balizar-lhe os movimentos, de democratizá-lo, de ampliar as arenas de conflito e resolução, e não de reprimi-los). Desprivatizá-lo significa desentranhar os "anéis burocráticos" que formam a imbricação histórica promíscua entre o público e o privado no Brasil. Essa avalanche, a partir do Governo Temer, colocou o Brasil num cenário de extremos retrocessos sociais, que foram aprofundados dentro do governo que o sucedeu tendo como aliado um suporte neoconservador que radicalizou diversos elementos da hegemonia aprofundada pelos governos do PT. No presente governo de Jair Bolsonaro, fica claro que as políticas para pobres eram "direitos sociais transitórios", não ajudaram a formação de subjetividades coletivas, necessárias à adesão a um projeto voltado aos interesses da classe trabalhadora, esvaziaram o Estado de conteúdo político, ampliaram valores morais dicotomizando a pobreza da desigualdade de classes e consequentemente serviram como mais um pretexto para as elites brasileiras (tão bem denominadas de 'elites do atraso', por Jessé de Souza, 2017) construíssem discursos moralizantes com relação a essas políticas.

As alternativas às "novas" expressões da "questão social" auferidas nos governos petistas se constituem em políticas voltadas para a pobreza e para a extrema pobreza. Nessa medida, tais políticas confluem para confirmar e legitimar a "subalternização" a que são submetidos vários segmentos da sociedade, por meio de benefícios que não constituem legítima apropriação dos resultados oriundos da riqueza socialmente produzida no Brasil, que é apropriada pela burguesia, marcando, como já destacado, a forte desigualdade social no país. O que se tem "são apenas débito a fundo perdido, preço a pagar pela sustentação de uma economia cuja dinâmica bane e descarta parcelas da população" (Yazbek, 2001, p. 36). Concordamos com Maria Carmelita Yazbek (2001) quando ela mencionou, no auge das mesmas, que com essas "políticas ad hoc, casuísticas, fragmentadas, sem regras estáveis e operando em redes obsoletas e deterioradas, corremos um risco de grave regressão de direitos sociais" (Yazbek, 2001, p. 37). Podemos dizer que tais regressões se confirmaram após o impeachment de Dilma Rousseff, em 31 de agosto de 2016.

Ao analisarmos as expressões da "questão social" no Brasil e as suas formas de enfrentamento na contemporaneidade, é imprescindível destacar que, embora haja o reconhecimento dos direitos constitucionalmente, os mesmos não vêm se constituindo historicamente como atributo das políticas sociais. No 
que concerne ao atendimento das necessidades sociais das camadas subalternizadas, administram-se favores, como consequência do marco histórico do clientelismo brasileiro, que se manifesta numa cultura política tuteladora, que corrobora para o não favorecimento do "protagonismo", muito menos, da emancipação dessas classes em nossa sociedade. O modelo construído pelo PT reforçou as abordagens despolitizadas da "questão social", colocando-a fora da esfera pública, fora da esfera dos direitos e, portanto, distante da efetivação da cidadania. Faz-se necessário ter a clareza que

[...] a universalidade no acesso aos programas e projetos sociais abertos a todos os cidadãos só é possível no âmbito do Estado. Este, ainda que seja um Estado de classe, dispõe de uma dimensão pública que expressa a luta pelos interesses da coletividade. Projetos levados a efeitos por organizações privadas apresentam uma característica básica que os diferencia: não se movem pelo interesse público, e sim pelo interesse privado de certos grupos e segmentos sociais, reforçando a seletividade no atendimento, segundo estabelecido pelos mantenedores (Iamamoto, 2001, p. 76).

Em suma, as estratégias presentes nas políticas sociais de enfrentamento da pobreza reforçaram tendências que cada vez mais buscam desresponsabilizar o Estado pela manutenção da ordem republicana e delegam cada vez mais tarefas de combate ao que chamam de exclusão ao mercado ou da própria sociedade capaz de legitimá-lo. Tais estratégias combinadas, diz Maria Lúcia Werneck Vianna (2007, p. 7),

[...] conferem estatuto de verdade absoluta à noção discutível de que é possível incluir segmentos social e economicamente marginalizados via programas pontuais de alívio à pobreza e fomento à autopromoção - importantes, sem dúvida, mas inócuos na ausência de projetos de desenvolvimento que gerem empregos dignos e que possam alterar as estruturas que reproduzem as desigualdades. Articuladas, por fim, ajudam a disseminar a ilusão de que a disponibilidade de capital social, linhas de microcrédito e rotas de "empoderamento" configuram versão popular do acesso ao capital propriamente dito e do ingresso nos círculos dos poderosos - por definição inexequíveis para os pobres -, e que, como esses, oferecem oportunidades de mobilidade social.

Com recursos muito baixos e condicionalidades para a manutenção dos benefícios, as políticas para a pobreza, como menciona Silva (2012), contribu- 
em para a contrarreforma do Estado por meio da focalização das políticas sociais. Para a autora, "são ainda forma de monetarizar e financeirizar as políticas sociais, pois operam com recursos monetários administrados por instituições bancário-finaceiras" (idem, p. 211). Não é demais lembrar, segundo Leher (2012, p. 17), que até mesmo os parcos recursos "repassados às famílias pelo Programa Bolsa família são distribuídos por meio do sistema bancário, através de cartões que movimentam, no conjunto, somas nada desprezíveis que totalizavam mais de R $\$ 15$ bilhões anuais". Obviamente, o comentário do autor se refere ao período analisado pelo mesmo.

Silva (2012, p. 223-224) observa que o ponto comum entre os programas de combate à pobreza é que os mesmos "trabalham no enfrentamento à pobreza e à miséria, ou seja, às expressões da 'questão social”'. E por se constituírem "por meio de repasses não operados diretamente pelo aparato estatal, eles remuneram terceiros para a realização desses serviços". Ou seja, "remuneram bancos para a realização dessas operações”. Assim sendo, a lógica fundamental dessas políticas, segundo a autora (idem), "é inserir a força de trabalho no mundo das finanças por meio do provimento de "bolsas" e transformar o cidadão de direitos em "cidadão-consumidor", fundamental à reprodução da acumulação capitalista”. Por isso, compreender e criticar os nexos constitutivos das chamadas políticas de combate à pobreza, exigem entender que "a conformação de uma determinada hegemonia nunca é um fenômeno que se encerra no terreno das ideias, envolvendo, sempre uma dimensão de supremacia econômica na sociedade civil" (Leher, 2012, p. 19).

O Brasil do século XXI é um Brasil que vivencia um projeto hegemônico em plena consonância com as exigências do capital financeiro. Faz-se mister tornar pensável,

[...] por meio da teoria, as profundas e desconcertantes transformações nas referências conceituais, nas noções, nos implícitos e nos pressupostos, em resumo, nas ideologias das políticas sociais empreendidas pelo Estado, por meio de políticas de governo e de uma miríade de parcerias público-privado (Leher, 2012, p. 15).

Nesse século, tivemos algumas inflexões das políticas sociais, todas agravando as formas de enfrentamento da questão social, na medida em que essas são espécies de gerenciamento da pobreza e se desvinculam da sua superação. 


\section{A Avalanche Ultraneoliberal}

Hoje, na segunda década do século XXI, apesar de o neoliberalismo ter confirmado que também no Brasil os seus sucessos ideológicos são visivelmente maiores do que os êxitos econômicos, ele continua sobrevivendo e sendo radicalizado sem grandes ameaças. Esse fato também deve ser atribuído à incapacidade da esquerda, até aqui, para construir formas hegemônicas alternativas para a sua superação. Bases essas que não podem deixar de se ocupar com a construção de um projeto de socialização do poder que seja articulado com a crise fiscal do Estado e capaz de desarticular as bases de legitimação do neoliberalismo, entre as quais se situa a passividade, o aumento dos níveis de pobreza, o desemprego e a desagregação social ${ }^{8}$.

Alguns exemplos de que o sucesso ideológico do neoliberalismo proporcionou um agigantamento da sua agenda transformando suas metas em uma verdadeira avalanche ultraneoliberal se confirma quando percebemos a velocidade das perdas de direitos sociais nos últimos três anos. A pandemia da Covid19 deixou ainda mais evidente o grau de letalidade a que as classes subalternas estão de fato submetidas ao serem desprovidas de tantos direitos.

Nesse contexto de aprofundamento da crise, o capital adota medidas que tendem a deteriorar ainda mais a condição de produção e de reprodução social, como já analisava Marx (2009) ao tratar da lei geral e fundamental do modo de produção capitalista. Nessa medida, o capital assume, nas palavras de Mandel (1982) um caráter predatório, expondo o seu sociometabolismo bárbaro e destrutivo (Mészáros, 2009), sem qualquer limite civilizatório (Netto, 2013).

Seja por meio do Golpe jurídico parlamentar (Michel Temer - 2016 a 2019) ou por meio de eleições diretas e democráticas (Jair Bolsonaro (2019 - em exercício), temos no Brasil o agravamento da crise social através da celeridade

${ }^{8} \mathrm{O}$ Brasil, em consonância com todos os países da América Latina, testifica que o (neo)liberalismo tem se confirmado como uma tendência generalizada no campo do enfrentamento da "questão social". Esperava-se, por parte de muitos, que o controle da inflação, representaria a abertura das portas para a retomada do crescimento econômico, a distribuição de renda, da geração de empregos e da extensão das políticas sociais, o que não teve êxito, como demonstram os indicadores sociais. Ao contrário, a estabilidade foi feita às custas do social, que, em vez de ser uma projeção da economia, tornou-se sua vítima. Nesta congruência, é mister destacar que o Brasil e toda a América Latina, constituem-se no laboratório privilegiado das experiências neoliberais, tornando-se a região mais instável do globo, em termos econômicos e sociais, refletindo na maior desordem social que o continente já experimentou (Soares, 2003). Os caminhos previstos atualmente não são otimistas, dado o quadro da avalanche neoliberal sobre os direitos, como temos buscado demonstrar. 
do ajuste fiscal e das medidas contrarreformistas. Disto, tem-se para o capital "condições ótimas" para o seu processo de acumulação e de concentração, à medida que disponibiliza trabalhadores "livres como os pássaros" (Marx, 2013), que aceitam trabalhar sob quaisquer condições e salários, uma vez que foram destituídos historicamente dos seus meios de vida e no tempo presente, também dos seus direitos sociais e trabalhistas, que no Brasil nunca se universalizaram, como demonstramos.

Dentre as medidas mais expressivas e aviltantes do Governo Temer, e que se desdobra em muitas outras, evidenciando a barbárie ultraneoliberal, temse a Emenda Constitucional no 95 (EC 95), aprovada em 15 de dezembro de 2016. Conhecida como a PEC 55 ou mais popularmente como a PEC do "fim do mundo", que instituiu um "Novo Regime Fiscal", restringindo o gasto público primário, destinado a direitos sociais fundamentais, como a saúde, a educação e a assistência social pelos próximos 20 anos (Brasil, 2020).

A EC 95 estabelece um teto de gastos para as despesas primárias. Dessa forma, o gasto público primário só poderá ser ampliado para cobrir a inflação do ano anterior. Isto é, não haverá aumento dos recursos financeiros, o que se tornará cada vez mais incompatível com as demandas pelos serviços sociais públicos, já que desconsidera o crescimento demográfico e a taxa de longevidade brasileiro.

Além da chamada PEC da morte, o governo Temer sancionou a PEC 31/20169 , que prorrogou até 2023 a Desvinculação das Receitas da União (DRU), cujo objetivo é a permissão para que a União utilize livremente 30\% dos recursos da seguridade social. Esse mecanismo, de acordo com Behring e Boschetti (2011), tem sido responsável por retirar orçamento significativo das políticas sociais, transferindo-o para o mercado financeiro, por meio do pagamento da dívida pública. Sendo um dos mais importantes mecanismos para gerar o superávit primário.

A redução orçamentária incidiu significativamente sobre a educação, que foi uma das áreas mais atingidas. O governo Bolsonaro, extinguiu cerca de 27.500 cargos em universidades públicas e vedou a abertura de concursos para 68 cargos, por meio do Decreto 10185/2019, objetivando o sucateamento da educação superior pública. Em reportagem realizada por Carta Capital, é possível ter noção do deletério quadro imposto por Bolsonaro à educação, por meio

\footnotetext{
${ }^{9}$ Senado Federal (Brasil). Senado aprova que prorroga a DRU até 2023. In Senado Federal (Brasil). Plenário. Brasília: Senado Federal, 2020. Disponível em: < https://www12.senado.leg.br/noticias/materias/2016/08/24/senado-aprovaproposta-que-prorroga-a-dru-ate-2023 > . Acesso em: 11 jan. 2020.
} 
de cortes de mais de $\mathrm{R} \$ 2$ bilhões de reais no orçamento do FIES para o ano de 2020. Além de cortes no investimento na educação básica, profissional e superior, cujo orçamento caiu de $\mathrm{R} \$ 2.2$ bilhões para $\mathrm{R} \$ 1.9$ bilhões em 2020 . Tivemos a paralisação de 7 cursos do PRONERA ${ }^{10}$, destinados à educação dos trabalhadores em 4 Estados. Neste mesmo ano, houve ainda cortes das bolsas ofertadas CAPES de mais $\mathrm{R} \$ 2.1$ bilhões de reais em relação ao ano anterior (Basílio, 2020).

Por meio do Decreto 9.741/2019, objetivou-se o contingenciamento das despesas discricionárias, bloqueando cerca de 34.955 bilhões do orçamento para o ano de 2019. De acordo com Júnior e Machado (2020), os ministérios mais atingidos por tal Decreto foram os da Educação e o de Minas e Energia. Do primeiro, tem-se a possibilidade de mais nichos de valorização rentáveis ao capital, por meio da ampliação das universidades privadas e à distância em todo o território nacional.

As propostas governamentais de Temer e de Bolsonaro, como é possível evidenciar, caminham a passos cada vez mais largos para a lógica da privatização das atividades estatais. Desse intuito, tem-se também o Future-se, que objetiva para as universidades federais a capacitação de suas próprias receitas, reestruturando, portanto, o seu financiamento.

As consequências da PEC da morte também foram deletérias para a política de assistência social. Só em dezembro de $2016^{11}$ o governo cancelou 469 mil benefícios do Programa Bolsa Família e bloqueou outros 667 mil, o que confirma a fragilidade dessas políticas que são removidas sem grandes dificuldades. Sob Bolsonaro, em 2020, estima-se que 400 mil famílias percam o acesso ao benefício, em função da redução de $7,8 \%$ do orçamento destinado ao programa para este ano ${ }^{12}$. Segundo reportagem da Carta Capital em 31 de janeiro de $2020^{13}$, 500 mil pessoas estão inscritas e aptas para receber o Bolsa Família, mas não conseguem acesso ao benefício. E esse número é ainda mais expressi-

\footnotetext{
${ }^{10}$ Chagas, Rodrigo. "MPF pede retomada de programa que incentiva acesso de assentados à universidade". Net, jan. 2020. Disponível em: < https://www.brasildefato.com.br/2019/09/13/mpf-pede-retomada-de-programa-que-incentiva-acesso-de-assentadosa-universidade/ $>$. Acesso em: 15 jan. 2020.

${ }^{11}$ Branco. Mariana. "Governo cancela 469 mil benefícios do Bolsa Família e congela 667 mil”. Net, jan. 2020. Disponível em:

< http://agenciabrasil.ebc.com.br/geral/noticia/2016-11/governo-cancela-469-mil-ebloqueia-667-mil-beneficios-do-bolsa-familia >. Acesso em: 11 jan. 2020.

12 Basílio, Ana Luiza. "Bolsonaro impõe menor orçamento da história a Minha Casa Minha Vida”. Net, jan. 2020. Disponível em:

< https://www.cartacapital.com.br/politica/bolsonaro-impoe-menor-orcamento-dahistoria-ao-minha-casa-minha-vida >/. Acesso em: 15 jan. 2020.
} 
vo, considerando aqueles que não estão inscritos no Programa, perfazendo um total de 3,8 milhões de famílias pobres ou miseráveis, que têm renda per capita mensal de até $\mathrm{R} \$ 178,00$ e de até $\mathrm{R} \$ 89,00$ reais, respectivamente. Do total das famílias desassistidas, $37 \%$ delas residem no Nordeste, o que demonstra as disparidades socioespaciais no Brasil.

Outro programa substantivo que teve os seus recursos drasticamente reduzidos foi o Minha Casa Minha Vida. Tivemos em outubro de 2016 a revogação do Projeto de Lei 4.960/2016, que regulava o Programa e os assentamentos. Em 2017, 72,5\% da meta da construção de moradias populares foram alcançadas. No referido ano, o governo teve uma queda histórica dos recursos recebidos, perfazendo um total de $94,6 \%$ do orçamento em relação ao ano de 2015 (Gadelha e Alves, 2020). O que se aprofundou ainda mais em 2019, quando o programa recebeu o menor orçamento da sua história.

Os governos ultraneoliberais também não escondem o seu objetivo de favorecer o agronegócio e a bancada ruralista, ao passo que negligenciam a demanda dos agricultores familiares, dos povos tradicionais e do Movimento dos Trabalhadores Sem Terra. Face a isso, é possível testificar o aprofundamento do compromisso dos governos ultraneoliberais com as predileções imperialistas, uma vez reconhecido o aviltamento do entreguismo e da privatização das reservas ambientais e do território dos povos originários, intensificando sobremaneira os processos de expropriação da terra ${ }^{14}$. Nessa perspectiva, há de se considerar a expressiva redução de $51 \%$ do orçamento destinado ao Ministério do Meio Ambiente.

É relevante ainda destacar, no que se refere à avalanche ultraneoliberal, a subtração de $90 \%$ do orçamento do Ministério da Cultura ${ }^{15}$, paralisando as suas atividades. Além das políticas destinadas às mulheres que também sofreram cortes substantivos no ano de 2019, tendo neste ano recebido o menor orçamento desde 2012, no combate ao enfrentamento da violência contra a mu-

13 Oliveira, Thais. "3,8 milhões de famílias pobres ou miseráveis estão fora do Bolsa Família". Net, jan. 2020. Disponível em: < https://www.cartacapital.com.br/sociedade/ 38-milhoes-de-familias-pobres-ou-miseraveis-estao-fora-do-bolsa-familia $>/$.

Acesso em: 11 jan. 2020.

14 Souza, De Oswaldo. "O que muda (ou sobra) para os índios com a reforma de Bolsonaro?”. Net, jan. 2020. Disponível em: < https://www.socioambiental.org/pt-br/ noticias-socioambientais/o-que-muda-ou-sobra-para-os-indios-com-a-reforma-de-

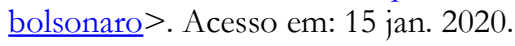

${ }^{15}$ Vilela, Pedro Rafael. "Com PEC, recursos da cultura terão corte de 90\%”. Net, jan. 2020. Disponível em: <https://www.brasildefato.com.br/2016/11/11/com-pecrecursos-da-cultura-terao-corte-de-90/>. Acesso em: 11 jan. 2020. 
lher ${ }^{16}$.

Com o claro objetivo de que a acumulação se dê cada vez mais pela esfera do não acesso ao direito ao trabalho, o governo Temer em 2017, instituiu o Plano Progredir, que objetiva capacitar jovens que recebem o Bolsa Família, para abrirem pequenos negócios, sob a lógica do empreendedorismo, com microcrédito ofertado pelo Estado. O trabalho com direitos vai sendo cada vez mais substituído pelo trabalho intermitente, pelo empreendedorismo e tantas outras formas precárias de inserção no "mundo do trabalho", conforme já vem evidenciando Antunes (2018) em seus estudos sobre a "nova morfologia" do trabalho no Brasil.

A intensificação da expropriação secundária (Fontes, 2012) concernente aos direitos trabalhistas continua ocorrendo sob o governo auspicioso ao capital de Jair Bolsonaro. Ao tomar posse, uma das primeiras medidas tomadas foi a extinção do Ministério do Trabalho, o que facilita o descumprimento dos contratos e das leis trabalhistas, que desde o governo Temer já vinha sendo alvo primário das investidas do capital.

Por meio da Portaria 604/2019, autorizou-se a 78 áreas de atuação profissional a trabalhar aos domingos e feriados, sem direito a adicional de remuneração. Disso, aumenta-se a extração da mais-valia absoluta (Marx, 2013).

Outra disposição palatável ao capital foi a Medida Provisória 881/2019, popularmente conhecida como a lei da liberdade econômica, convertida na Lei 13.874/2019, que instituiu a revisão das normas reguladoras da saúde e da segurança do trabalho. Tal medida favoreceu as empresas, uma vez que, retira direitos dos trabalhadores e não garante a efetivação dos direitos que ainda foram preservados, segundo reportagem intitulada "MP da liberdade econômica retira direitos e afrouxa a lei trabalhista" ${ }^{\prime 17}$, publicada em 13 de agosto de 2019 no site Carta Capital.

Outra medida agressiva aos trabalhadores foi a aprovação da PEC 287/2016, que versa sobre a Reforma da Previdência, em 2019. Seus resultados já são deletérios, sobretudo, para os segmentos mais subalternizados da classe trabalhadora. Isso decorre, uma vez que a sua proposta é de aumentar o tempo

\footnotetext{
${ }^{16}$ Sul 21. "Orçamento do programa de proteção à mulheres de 2019 é 6 vezes menor que o de 2015". Net, jan. 2020. Disponível em: < https://www.sul21.com.br/ultimasnoticias/geral/2019/03/orcamento-do-programa-de-protecao-a-mulher-de-2019-e-6vezes-menor-que-o-de-2015/>. Acesso em: 15 jan. 2020.

${ }^{17}$ Repórter Brasil. "MP da liberdade econômica retira direitos e afrouxa a lei trabalhista". Net, jan. 2020. Disponível em:

< https://www.cartacapital.com.br/sociedade/mp-da-liberdade-economica-retiradireitos-e-afrouxa-a-lei-trabalhista/ $>$. Acesso em: 30 jan. 2020.
} 
de contribuição e aumentar a idade mínima para a aposentadoria, permitindo que os sujeitos trabalhem "até morrer". Sendo, portanto, fundamental ao capital, dado que para sobreviver, esses sujeitos aceitarão trabalhar sob quaisquer condições e salários.

Ao mesmo tempo, tal medida foi completamente favorável para o capital, pois além de dispor ao mercado de trabalho, trabalhadores "livres como os pássaros" (Marx, 2013), abriu espaço para a mercantilização das necessidades sociais, por meio do incentivo à ampliação da previdência privada, para aqueles trabalhadores que podem pagar por ela (Fontes, 2012). Nessa medida, tem-se a supercapitalização das políticas de satisfação das necessidades sociais mais básicas e elementares (Mandel, 1982).

Com o mesmo objetivo, de "assalto ao fundo público", tem-se a MP $871 / 2019^{18}$, hoje Lei n ${ }^{\circ} 13.846 / 2019^{19}$, cujo caráter central é o de revisar benefícios de prestação continuada do INSS, a fim de reduzir despesas. Inclusive, contraditoriamente, favorecendo bônus aos peritos que realizarem mais perícias médicas, negativando os sujeitos outrora contemplados por tal benefício.

Muitas outras PECs perversas, de tonalidade de reformas econômicas, foram enviadas, mas ainda não foram aprovadas. Todas elas foram apresentadas como prioridades para aprovação no ano de 2020, no sentido de alavancar ainda mais as contrarreformas de financeirização da política social postas na atual agenda ultraneoliberal.

A avalanche ultraneoliberal já tem muito mais exemplos do que os mencionados aqui. E os custos sociais do ultraneoliberalismo se apresentam todo dia na barbarização da vida em nosso país, que vem enfrentando a pandemia da Covid-19 com total desrespeito as vítimas e desresponsabilizando o Estado das medidas de contenção do avanço e cuidados com a doença.

\footnotetext{
18 Senado Federal (Brasil). Sancionada com vetos medida provisória que combate fraudes no INSS. In Senado Federal (Brasil). Política. Brasília. Senado Federal. Disponível em:

< https://www12.senado.leg.br/noticias/materias/2019/06/19/sancionada-com-vetosmedida-provisoria-que-combate-fraudes-no-inss $\geq$. Acesso em: 12 jan. 2020.

${ }_{19}$ Planalto Federal (Brasil). Lei no: 13.846, de 18 de junho de 2019. In Planalto Federal (Brasil). Presidência da República. Brasília. Planalto Federal. Disponível em: <http://www.planalto.gov.br/ccivil 03/ Ato2019-2022/2019/Lei/L13846.htm>.

Acesso em: 12 jan. 2020.
} 


\section{Considerações Finais}

É indiscutível que enquanto concepção de enfrentamento da "questão social", as estratégias predominantes que se autodefinem como inovadoras na política social contemporânea se mostraram bem menos ambiciosas do que aquelas que se propuseram renovar. Sobretudo, se mostraram menos ousadas, na medida em que se eximiram "da discussão teórica, ocultando-se sob os véus da empiria e do consenso" (Vianna, 2020, s/p). Nesse contexto, não seria exagero afirmar que a expansão dessas políticas foi acompanhada pela mercantilização de serviços públicos fundamentais. Como mencionou Maranhão (2006, p. 42-43),

[...] o aumento dos investimentos em uma política para os pobres esconde a abertura de novos e lucrativos mercados de investimento para o capital privado, em detrimento do serviço público. Assim é que, a "inclusão dos excluídos" serve de discurso de legitimação para o avanço do capital sobre os ativos públicos e para o andamento das reformas neoliberais.

A questão da pobreza impõe desafios políticos muito mais amplos do que os que foram engendrados pelo PT, sob recomendação dos organismos internacionais, principalmente pelo Banco Mundial. A possibilidade das chamadas políticas sociais da pobreza reverterem por si só a pobreza e obter resultados de redistribuição da riqueza é impossível, o que demonstrou a pobreza dessas políticas. A erradicação e superação da pobreza dependem da ação combinada da articulação e da reconstrução da matriz do Estado social e da sua capacidade de reverter ou mitigar as fontes estruturais da desigualdade social. $\mathrm{O}$ que foi feito através dessas políticas foi um gerenciamento da pobreza, divorciado da possibilidade de sua superação e auxiliando também a financeirização dessa política para favorecimento do capital hegemônico. Não se pode enfrentar a pobreza sem transformar a base econômica. Com essas políticas pobres para pobres, os valores morais foram acionados, construindo um descentramento das subjetividades do debate sobre os direitos dos trabalhadores como classe social, para o debate da ajuda aos pobres enquanto tais, sem percepção de classe e de direitos. Todos os nexos das políticas de gerenciamento da pobreza que os governos do PT tornaram protagonistas em seus mandatos, contribuíram para manufaturar o consenso que ajudou a construir uma passivização das camadas mais empobrecidas da classe trabalhadora. Vale lembrar que nos governos do PT parecia 
existir uma lógica moral de que os pobres "bons" receberiam o Bolsa Família, e os pobres "maus" o encarceramento. É imprescindível ressaltar que os governos de Lula foram recordistas de taxas de encarceramento.

Na primeira eleição de Luiz Inácio Lula da Silva, em 2002, seu programa de governo apontava a segurança pública como uma das prioridades, e defendia um maior protagonismo do governo federal para a redução da violência. A candidatura Lula apresentava o compromisso com uma política de controle de armas, e com a preocupação com o combate à impunidade para crimes praticados por organizações criminosas e contra os movimentos sociais e os direitos humanos. Contudo, não foi assim que ocorreu. O índice de encarceramento foi o maior da história do Brasil, sendo quase $90 \%$ de pobres e negros.

[...] os governos dirigidos pelo PT no Brasil não tiveram a capacidade para construir uma efetiva hegemonia de uma concepção de segurança pública vinculada à afirmação de direitos e ao funcionamento adequado e republicano dos órgãos responsáveis pela persecução criminal. Perderam também a possibilidade política de incidir sobre outras esferas de governo, como os estados e municípios, e mesmo outras dimensões institucionais, como parlamento e judiciário, para a mudança de orientação das decisões judiciais e a ampliação de um sistema legal capaz de reestruturar os órgãos policiais e implementar mecanismos eficazes de controle. Chegamos assim ao início de um novo governo, ainda na perspectiva da esquerda, mas com o crescimento ininterrupto das taxas de encarceramento, o aumento dos níveis de criminalidade violenta, e o recrudescimento dos movimentos de Lei e Ordem, ameaçando as poucas conquistas até aqui alcançadas e lançando uma sombra de dúvida sobre o futuro das políticas penais no Brasil (Azevedo e Cifali, 2015, p. 21).

Podemos dizer nessa direção, que a criminalização dos pobres também foi ampliada nesse período que deu centralidade ao gerenciamento da pobreza, seja pelo Bolsa Família, seja pelo encarceramento.

Se por um lado, o fato de estarmos vivenciando governos ultraneoliberais com expressões inegavelmente de cunho fascistanos deixa saudosos do passado recente, sem dúvida esse passado é fundamental para compreendermos o presente. A avalanche ultraneoliberal, não pode ser compreendida sem entendermos a hegemonia construída pelos governos do PT. Como observou Francisco de Oliveira (2007, p. 6), uma espécie de hegemonia às avessas.

O consentimento sempre foi o produto de um conflito de classes em que 
os dominantes, ao elaborarem sua ideologia, que se converte na ideologia dominante, trabalham a construção das classes dominadas à sua imagem e semelhança. Esse é o núcleo da elaboração de Marx e Engels n' A Ideologia Alemà, que o pequeno grande sardo desdobrou admiravelmente. Está-se frente a uma nova dominação: os dominados realizam a "revolução moral" - derrota do apartheid na África do Sul; eleição de Lula e Bolsa-Família no Brasil - que se transforma, e se deforma, em capitulação ante a exploração desenfreada.

Os termos de Marx e Engels, da equação "força + consentimento" que forma a hegemonia, desaparece o elemento "força". E o consentimento se transforma no seu avesso: não são mais os dominados quem consentem na sua própria exploração. São os dominantes - os capitalistas e o capital, explicite-se - que consentem em ser politicamente conduzidos pelos dominados, à condição de que a "direção moral" não questione a forma da exploração capitalista. É uma revolução epistemológica para a qual ainda não dispomos da ferramenta teórica adequada. Nossa herança marxista-gramsciana pode ser o ponto de partida, mas já não é o ponto de chegada.

Temos claro que o modelo construído pelo PT reforçou as abordagens despolitizadas da "questão social", e ainda, contribuiu para a manufatura de um consenso pacificado sobre a questão da pobreza e do fortalecimento dos setores bancários em nosso país. Portanto, tal modelo não foi algo desvinculado dos elementos aprofundados pela atual avalanche ultraneoliberal. Em verdade,

[...] a história só surpreende aos que de história nada entendem. Há os que a ignoram, e outros que a temem. Os que se recusam a compreendêla e os que estão socialmente impedidos de fazê-lo. Se os pormenores não são, de fato, previsíveis, dada a infinidade de fatores intervenientes, sempre conhecíveis de modo apenas aproximado; se os contornos, pois, só ganham corpo na própria hora em que se efetivam os processos, do mesmo modo que os eventos não são rigidamente programáveis, em seus dias e horas; por outro lado, ao contrário disto, as grandes linhas de tendência, a necessária ocorrência dos acontecimentos básicos são amplamente discerníveis, divisáveis mesmo no longo prazo. Basta admitir a existência de uma ciência da história e que haja disposição social para rigorosamente se submeter à sua lógica. Tudo isso, obviamente, não é nada fácil. Contudo, no que consiste impulsionar os partos da história, se não, nos fatos, intervir à luz da própria lógica destes? (Chasin, 2000, p. 34). 
Assim sendo, é importante destacar que sempre nos pareceu incontestável (Freire, 1991) que, para compreender os rumos da política social no Brasil, é preciso apreender a sociedade nos marcos políticos, onde ela não apenas se engendra como também opera.

\section{Referências}

ABRIL. "Desigualdade social no país aumenta pelo $17^{\circ}$ semestre seguido". Net, jan. 2020. Disponível em: < https://veja.abril.com.br/economia/desigualdadesocial-no-pais-aumenta-pelo-17-trimestre-seguido-diz-fgv/.> Acesso em: 14 jan. 2020.

ANTUNES, Ricardo. O privilégio da servidão: o novo proletariado de serviços na era digital. São Paulo: Boitempo, 2018.

AZEVEDO, Rodrigo de e CIFALI, Ana Cláudia. Política criminal e encarceramento no Brasil nos governos Lula e Dilma: elementos para um balanço de uma experiência de governo pós-neoliberal. Civitas- Revista de Ciências Sociais, vol.15, n.1, p. 105-127. 2015.

BASÍLIO, Ana Luiza. Future-se: entenda os principais pontos do programa do MEC. Net, jan. 2020. Disponível em: < https://www.cartacapital.com.br/edu-

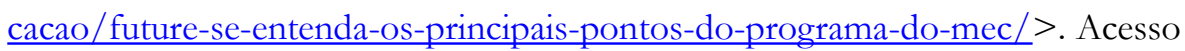
em: 30 jan. 2020.

BEHRING, Elaine e BOSCHETTT, Ivanete. Política Social: fundamentos e história. 9. ed. São Paulo: Cortez, 2011.

BORON, Atílio. A sociedade civil depois do dilúvio (neo)liberal. In: SADER, Emir e GENTILI, Pablo (org.). Pós-neoliberalismo: as políticas sociais e o Estado Democrático. São Paulo, Paz e Terra, 1995. p. 63-77.

. Os 'novos leviatãs' e a pólis democrática: neoliberalismo, decomposição estatal e decadência da democracia na América Latina. In; SADER, Emir e GENTILI, Pablo (org.). Pós-neoloiberalismo II: que Estado para que democracia? Petrópolis: Vozes, 1999.

CARVALHO, José Murilo de. Cidadania no Brasil: o longo caminho. Rio de Janeiro: Civilização Brasileira, 2001.

CHASIN, José. A miséria brasileira: 1964-1994 - do golpe militar à crise social. Santo André: Estudos e Edições Ad Hominem, 2000. 
COUTINHO, Carlos Nelson. "Notas sobre cidadania e modernidade". Revista Praia Vermelha: Estudos de Política e Teoria Social. v. 1, p.145-165. 1997.

DAGNINO, Evelina e ALVAREZ, Sonia (org.). Os movimentos sociais, a sociedade civil e o 'terceiro setor' na América Latina: reflexões teóricas e novas perspectivas. IFCH/UNICAMP. v. 1, n. 98, p. 18-34, 2001.

DEMIER, Felipe. Depois do Golpe: a dialética da democracia blindada no Brasil. Rio de Janeiro: Mauad X, 2017, p. 65-110.

FREIRE, Silene de Moraes. As armadilhas da recente notoriedade da sociedade civil no Brasil. In FREIRE, Silene de Moraes, FREIRE, Lúcia e CASTRO, Alba Tereza (org.). Serviço social, política social e trabalho. São Paulo: Cortez, 2006. p. 75-97.

Cultura política e revolução burguesa no Brasil: a instrumentalidade do pensamento autoritário (1930-1945). Rio de janeiro. Editora Gramma, 2020.

Estado, democracia e questão social no Brasil. In BRAVO, Maria Inês Souza e PEREIRA, Potyara (org.). Política Social e Democracia. 2. ed. São Paulo: Cortez e Rio de Janeiro: UERJ, 2002. p. 149-172.

. e BARBOZA, Douglas. A decomposição do Estado e o protagonismo da sociedade civil no enfrentamento da questão social no Brasil: os dilemas da cidadania e da democracia na contemporaneidade. Textos e Contextos. n. 6, ano V, p. 1-21, 2006.

FONTES, Virgínia. O Brasil e o Capital-imperialismo: teoria e história. 3. ed. Rio de Janeiro: Editora UFRJ. 2012.

GADELHA, Igor e ALVES, Murilo. Governo cumpre só 13,5\% da meta do Minha Casa para mais pobres. Net, jan. 2020. Disponível em: $<\underline{\text { https://eco- }}$ nomia.estadao.com.br/noticias/geral,governo-cumpre-so-13-5-da-meta-dominha-casa-para-mais-pobres, 70002149698 > . Acesso em: 27 dez. 2019.

GENTILI, Pablo. A privatização da política educacional: dez questões. Boletim LPP -UERJ, Rio de Janeiro, n. 1, p.12. 2000.

IAMAMOTO, Marilda Villela. A questão social no capitalismo. Temporalis: Brasília, ano 2, n.3, p. 33-40, p. 2001.

Trabalho e indivíduo social: um estudo sobre a condição operária na agroindústria canavieira paulista. São Paulo, Cortez, 2001.

JÚNIOR, Janary e MACHADO, Ralph. “Governo decide bloquear quase R\$ 
35 bi em despesas do Orçamento de 2019". Disponível em: < $\underline{\text { https://www.- }}$ camara.leg.br/noticias/554580-GOVERNO-DECIDE-BLOQUEAR-QUASER\$-35-BI-EM-DESPESAS-DO-ORCAMENTO-DE-2019>. Acesso em: 12. jan. 2020.

LEHER, Roberto. Ideologia do desenvolvimento, pobreza e hegemonia. In: MOTA, Ana Elizabete (org.). Desenvolvimentismo e construção de hegemonia: crescimento econômico e reprodução da desigualdade. São Paulo: Cortez, 2012, p. 7-19.

MANDEL, Ernest. Capitalismo Tardio. São Paulo: Abril Cultural, 1982.

MARANHÃO, Cezar Henrique. Acumulação, trabalho e superpopulação. Crítica ao conceito de exclusão social. In: MOTA, Ana Elizabete (org.). O Mito da assistência social: ensaios sobre Estado, política e sociedade. Recife: UFPE, 2006, p. 15-46.

MARX, Karl. A lei geral da acumulação capitalista. In: O capital: crítica da economia política. Livro I, vol. II. $23^{a}$ ed. Rio de Janeiro: Civilização Brasileira, 2009.

A assim chamada acumulação primitiva. In: MARX, Karl. O capital: crítica da economia política. Livro I: O processo de produção do capital. Trad. Rubens Enderle. São Paulo: Boitempo, 2013, p. 959-989.

MAURIEL, Ana Paula Ornellas. Combate à pobreza e desenvolvimento humano: impasses teóricos na construção da política social na atualidade. 2008. 341 p. Tese (Doutorado em Ciências Sociais), Universidade Estadual de Campinas, Campinas, 2008.

MÉSZÁROS, István. A crise estrutural do capital. São Paulo: Boitempo, 2009.

MERKLEN, Denis. Pobres ciudadanos. Buenos Aires: Ed. Gorla, 2005.

MOTA, Ana Elizabete. A cultura da crise e seguridade social: um estudo sobre as tendências da previdência e da assistência social brasileira nos anos 80 e 90. São Paulo: Cortez, 1995.

NETTTO, José Paulo. Uma face contemporânea da barbárie. Revista Novos Rumos, v. 50, n. 1, 2013.

OLIVEIRA, Francisco. Hegemonia às avessas. Tribuna livre da luta de classes. 4. ed. 2007. 
. Um profeta pessimista. Revista Fórum. São Paulo: Editora Publisher Brasil, p. 8-13, 2007.

. Privatização do público, destituição da fala e anulação da política: o totalitarismo neoliberal. In: OLIVEIRA, Francisco e PAOLI, Maria Celia. (org.). Os sentidos da democracia. Petrópolis: Vozes, 1999, p. 55-82.

SEMERARO, Giovanni. Gramsci e a sociedade civil. Petrópolis: Vozes, 2001.

Senado Federal (Brasil). Proposta de Emenda à Constituição nº 55, de 2016 PEC do teto dos gastos públicos. Disponível em: $<\underline{\text { https: / /www25.senado.leg.- }}$ br/web/atividade/materias/-/materia/127337?o $=\mathrm{c} 11>$. Acesso em: 11 jan. 2020.

SERNA, Miguel. Pobreza y políticas de la pobreza: desafios para La construccción de laciudadanía social em elUruguay contemporâneo. In SERNA, Miguel (org.). Pobreza y (des)igualdad em Uruguay: una relaciónen debate. Clacso: Uruguay, 2010, p. 135-154.

SILVA, Giselle Souza da. Transferência de renda e monetarização das políticas sociais: estratégias da captura do fundo público pelo capital portador de juros. In Salvador Evilásio; Behring, Elaine; Boschetti, Ivanete e Granemann, Sara (org.). Financeirização, fundo público e política social. São Paulo Cortez, 2012. p. 209-240.

SOARES, Laura. O desastre social: os porquês da desordem mundial. Rio de Janeiro: Record, 2003.

TELLES, Vera da Silva. Pobreza e cidadania. São Paulo: Editora 34, 2001.

VIANNA, Maria Lúcia Werneck. Constatação perturbadora. Jornal da UFRJ, Rio de Janeiro, p. 16, maio de 2007.

Hiper-realidade ou hipoteoria? Especial para Gramsci e o Brasil.

Net. Jan. 2020. Disponível em: $<$ https://www.acessa.com/gramsci/?page=visualizar\&id=764> . Acesso em: 20 jan. 2020.

WACQUANT, Loïc. Punir os pobres: a nova gestão da pobreza nos Estados Unidos. Rio de Janeiro: Revan/Instituto Carioca de Criminologia, 2002.

YAZBEK, Maria Carmelita. Pobreza e exclusão social: expressões da questão social no Brasil. Temporalis: Brasília, ano 2, n.3, p. 33-40, p. 2001. 